\title{
PENGARUH KOMPENSASI TERHADAP EFEK TIVITAS KARYAWAN BMT SEPTA BINA USAHA DI DAERAH KOTA PEKANBARU
}

\author{
Zulkifli Rusby \& Edistanur \\ Dosen Fakultas Pendidikan Agama Islam Universitas Islam Riau \\ Email : zulkiflirusby@yahoo.com
}

\begin{abstract}
ABSTRAK
Tujuan penelitian ini adalah untuk menganalisis pengaruh kompensasi terhadap efektivitas karyawan BMT Septa Bina Usaha di daerah Kota Pekanbaru. Dimana dalam ajaran Islam upah atau kompensasi yang layak, bukanlah suatu konsesi, tetapi suatu hak asasi, yang dapat dipaksakan oleh seluruh kekuasaan negara. Penelitian ini merupakan penelitian kuantitatif yang bersifat korelasi dengan menggunakan analisis regresi linear sederhana. Populasi dari penelitian ini adalah seluruh karyawan BMT Septa Bina Usaha dengan metode pengambilan sampel menggunakan metode sensus. Hasil penelitian ini menemukan bahwa ada pengaruh secara signifikan antara kompensasi terhadap efektivitas kerja karyawan dengan tingkat efektivitas kerja karyawan termasuk dalam tingkatan tinggi, yaitu 5 atau 62,5. Adapun saran untuk pengelola BMT agar memberikan training-training diluar jam kerja kepada karyawannya, agar efektivitas kerja tersebut semakin baik.
\end{abstract}

Kata Kunci : Kompensasi, Karyawan BMT, Efektivitas Kerja, BMT Septa Bina Usaha.

\section{ABSTRAK}

The purpose of this research is to analyze the effect of compensation on the effectiveness of BMT Septa Bina Usaha employee in Pekanbaru. Whereas in Islamic teachings wages or appropriate compensation is not a concession, but a human right, which can be imposed by all state powers. This research is a quantitative research that is correlated using simple linear regression analysis. The population of this research is all employees of BMT Septa Bina Usaha within sampling method using census method. The results of this research found that there is a significant influence between compensation and work effectiveness of employees within the level of work effectiveness is 5 or 62.5. The suggestion for BMT managers is to provide training outside of working hours to their employee, so that the work effectiveness is getting better.

Keywords: Compensation, BMT Employees, Work Effectiveness, BMT Septa Bina Usaha. 


\section{PENDAHULUAN}

Pada era globalisasi sekarang ini setiap perusahaan menuntut agar kompensasi yang dibayarkan memperoleh imbalan dan prestasi kerja yang lebih besar dari karyawan, supaya perusahaan mendapatkan laba dan kontinuitas perusahaan terjamin. Kompensasi yang dimaksud dalam penelitian ini adalah imbalan berupa uang atau bukan uang (natura), yang diberikan kepada karyawan lihat (Kamus Bahasa Indonesia, 2001). Tentu berdasarkan lama kerja dan keahlian yang dimiliki oleh seorang karyawan.

Dalam ajaran Islam upah atau kompensasi yang layak, bukanlah suatu konsesi, tetapi suatu hak asasi, yang dapat dipaksakan oleh seluruh kekuasaan negara (Abdul Manan, 1997) Bersabda Nabi yang artinya "Upah kompensasi seorang buruh harus dibayarkan kepadanya sebelum keringat dibadannya kering" Selanjutnya, diriwayatkan dari Ibnu Majah bahwa Nabi SAW bersabda yang artinya "Kewajiban para majikan hanya menerima pekerjaan yang mudah dilakukan oleh para karyawannya. Janganlah memperkerjakan mereka sedimikian rupa sehingga berakibat buruk bagi kesehatannya."

Dalam kebanyakan organisasi, beberapa tugas menuntut keterampilan tinggi, yang lain dapat dikerjakan oleh mereka yang tidak terlatih. Jika semua buruh melakukan tiap langkah katakanlah proses manufaktur sebuah organisasi, semuanya mempunyai keterampilan yang diperlukan untuk melakukan pekerjaan, baik pekerjaan yang paling menuntut kemampuan keterampilan yang diperlukan untuk melakukan pekerjaan, baik pekerjaan yang paling menuntut kemampuan keterampilan tertentu maupun yang tidak menuntut keterampilan. Buruh yang terampil akan mendapat bayaran yang lebih dari pada buruh yang tidak terampil $\begin{array}{lrr}\text { dan upah mereka cenderung } & \text { crinkan }\end{array}$ keterampilan, membayar pekerja yang sangat terampil untuk mengerjakan tugas yang mudah merupakan suatu penggunaan sumber daya organisasi yang tidak efisien (Veithzal, 2004).

Kalau analisis kenyataan yang ada membuktikan bahwa dengan spesialisasi kerja tidak jarang akan dapat menimbulkan kebosanan kelelahan, stres, produktivitas rendah, kualitas buruk, bolos kerja meningkat dan tingkat keluaran karyawan tinggi dan lebih besar daripada keuntungan ekonomis. Lalu timbul pertanyaan apakah terdapat hubungan antara kompensasi dengan efektivitas kerja karyawan dan apakah terdapat hubungan Manajemen dengan kinerja Karyawan.

\section{TINJAUAN PUSTAKA \\ Pengertian Kompensasi}

Kompensasi adalah pendapatan yang berbentuk uang, barang langsung atau tidak langsung yang diterima karyawan sebagai imbalan atas jasa yang diberikan kepada perusahaan (Hasibuan, 2008)

Menurut William B. Werdher dan Keith Davis kompensasi adalah apa yang seorang pekerja terima sebagai balasan dari pekerjaan yang diberikannya. Baik upah perjam atau gaji periodik didesain dan dikelola oleh bagian personalia (Hasibuan, 2008).

Andrew F. Sikula mengatakan kompensasi adalah segala sesuatu yang dikonstitusikan atau dianggap sebagai suatu balas jasa atau ekuivalen.

Seseorang akan melakukan apa saja untuk mendapatkan gaji atau imbalan. Jenis imbalan yang dapat dialokasikan dalam suatu organisasi lebih rumit. Ada imbalam langsung dan juga tidak langsung (berupa uang). Ada dua jenis imbalan, pertama imbalan intrinsik, yaitu imbalan individu yang diterima untuk diri mereka. Kedua, 
imbalan ekstrinsik yaitu imbalan yang diterima dari lingkungan disekitar konteks kerja itu (Veithzal, 2004).

Teori upah pada umumnya adalah teori produk marjinal. Menurut teori ini upah ditentukan oleh keseimbangan antara kekuatan permintaan dan persediaan. Dengan mengasumsikan penyediaan tenaga kerja dalam suatu jangka waktu yang panjang dan konstan, maka permintaan akan buruh dalam masyarakat kapitalis, datang dari majikan yang mempekerjakan seribu orang lain, seolah-olah merupakan suatu gabungan yang ketat dari seribu unit dikalangan pembeli di pasaran tenaga kerja" (Abdul Mannan, 1997).

Macam-macam Kompensasi

a. Kompensasi langsung (Direct Compensation) berupa gaji, upah, upah insentif, benefit dan service. Menurut Andrew F Sikula Gaji adalah kompensasi tetap yang dibayarkan kepada pemangku jabatan, pimpinan atau posisi klerek, atas dasar teratur seperti tahunan, caturwulan, bulanan, atau mingguan.

b. Kompensasi tidak langsung (Indirect Compensation). Berupa Employee welfare atau kesejahteraan karyawan yaitu tunjangan kesehatan dan tunjangan perumahan.

\section{Asas-asas Kompensasi}

Terdiri dari asas adil dan asas layak dan wajar, sedangkan menurut Islam meliputi asas kebebasan dan kesukarelaan, asas menolak Mudharat dan mengambil manfaat, asas berkeadilan dan berimbang, asas kebajikan dan asas kekeluargaan dan persamaan derajat.

\section{Sistem dan Kebijaksanaan}

a. Sistem kompensasi terdiri sistem waktu, sistem hasil dan sistem borongan.

b. Kebijaksaan kompensasi disusun dengan unsur-unsur yang terdiri dari kompensasi langsung (gaji, upah, upah insentif). Kompensasi tidak langsung (kesejahteraan) berbentuk uang dan barang (natura) supaya dapat merangsang gairah dan kepuasan kerja karyawan serta mendorong terwujudnya sasaran perusahaan. (Hasibuan, 2008).

c. Waktu pembayaran kompensasi yang tepat. Pembayaran yang tepat akan memberikan dampak positif bagi karyawan dan diinformasikan secara jelas kepada karyawan supaya bermanfaat kepada semua pihak. (Hasibuan, 2008)

\section{Faktor yang Mempengaruhi Besarnya Kompensasi}

Terdiri dari penawaran dan permintaan tenaga kerja, kemampuan dan kesediaan perusahaan, serikat buruh atau organisasi karyawan, produktivitas kerja karyawan, pemerintah dengan undang-undang dan keppresnya, biaya hidup, posisi jabatan karyawan, pendidikan dan pengalaman karyawan, kondisi perekonomian nasional, serta jenis dan sifat pekerjaan. (Hasibuan, 2008)

\section{Efektivitas kerja}

Indikator efektivitas kerja karyawan dalam melaksanakan tugasnya yaitu:

a) Kemampuan dalam penerapan sistem dan prosedur kerja baru yang lebih baik di lingkungan unit kerja atau organisasi tempat bekerja saat ini.

b) Kemampuan dalam penerapan metode baru dalam penyelesaian masalah yang dihadapi di lingkungan unit kerja atau organisasi tempat bekerja saat ini.

c) Sikap keberanian dalam mengantisipasi dan mengatasi berbagai bentuk penyimpangan yang terjadi di lingkungan unit kerja atau organisasi tempat bekerja saat ini.

d) Sikap proaktif dalam bekerja .

e) Kemampuan dalam penerapan gaya kepemimpinan baru yang lebih baik 
di lingkungan unit kerja atau organisasi tempat bekerja saat ini.

f) Kemampuan dalam memotivasi orang lain atau staf (bawahan) dalam bekerja.

g) Kemampuan dalam meningkatkan kemandirian orang lain atau staf (bawahan) dalam bekerja.

h) Kemampuan dalam penerapan sistem transparansi dalam berbagai hal yang terkait dalam pelaksanaan tugas/pekerjaan di lingkungan unit kerja atau organisasi tempat bekerja.

i) Kemampuan dalam menerapkan sistem pengawasan dan pengendalian berbagai hal yang terkait dengan pelaksanaan tugas/pekerjaan di lingkungan unit kerja atau organisasi tempat bekerja.

j) Percaya diri dalam bekerja.

k) Perhatian lebih terhadap berbagai bentuk laporan langsung, baik dari staf (bawahan) maupun masyarakat yang tidak puas terhadap kepemimpinan atau pelayanan yang diberikan oleh unit kerja atau organisasi tempat bekerja saat ini.

1) Intensitas dalam melontarkan ide-ide baru (inovasi) dalam setiap kesempatan.

m)Kemampuan dalam melakukan koordinasi antar unit kerja di lingkungan unit kerja dan organisasi tempat bekerja.

n) Kemampuan dalam merumuskan visi pribadi maupun unit kerja atau organisasi tempat bekerja.

\section{Pengaruh Kompensasi terhadap Efektivitas Kerja Karyawan}

Pemberian kompensasi, baik besarnya, susunannya maupun waktu pembayarannya dapat mendorong gairah kerja dan keinginan karyawan untuk mencapai efektivitas kerja yang optimal sehingga membantu terwujudnya sasaran perusahaan.

Pemberian kompensasi yang
ditetapkan dengan baik akan

memberikan motivasi kerja bagi karyawan. Besarnya kompensasi harus ditetapkan berdasarkan analisis pekerjaan, spesifikasi pekerjanan, posisi jabatan, konsistensi eksternal, serta berpedoman kepada keadilan dan undang-undang perburuhan. Dengan kebijaksanaan tersebut diharapkan dapat memberikan kepuasaan kepada semua pihak.

Pembayaran kompensasi yang tepat waktu juga akan memberikan dampak yang positif bagi efektivitas kerja karyawan. (Hasibuan, 2008)

\section{METODE PENELITIAN}

\section{Disain Penelitian}

Penelitian ini merupakan penelitian kuantitatif yang bersifat korelasi dan terdiri dari dua variabel, yaitu variabel bebas dan variabel terikat. Variabel bebas dalam penelitian ini adalah "kompensasi", sedangkan variabel terikat adalah "efektivitas karyawan".

Penelitian ini di lakukan di BMT Septa Bina Usaha di Jalan kaharuddin Nasution Pekanbaru, dan yang menjadi objek dalam penelitian ini adalah karyawan di BMT Septa Bina Usaha. Sedangkan populasi dari penelitian ini adalah seluruh objek penelitian yang berjumlah 8 dengan metode pengambilan sampel adalah metode sensus. Metode pengumpulan data melalui angket yang disebarkan ke seluruh responden penelitian.

\section{Teknik Analisa Data}

Menggunakan formula regresi sederhana yaitu $\mathrm{Y}=\mathrm{a}+\mathrm{bx}+\mathrm{c}$. Untuk mencari nilai a dan $\mathrm{b}$ digunakan rumus:

$$
\begin{aligned}
& a=\frac{\sum y-\sum x}{n} \\
& b=\frac{n \sum x y-\sum x y-\sum x \sum y}{n \sum x-\left(\sum x\right)}
\end{aligned}
$$


Untuk melihat kuat dan lemahnya pengaruh kompensasi digunakan analisis korelasi dengan rumus :

$$
\mathrm{r}=\frac{\mathrm{n}\left(\sum \mathrm{xy}\right)-\left(\sum \mathrm{x}\right) \cdot\left(\sum \mathrm{y}\right)^{2}}{\left.\sqrt{\left\{\mathrm{n}\left(\sum \mathrm{x}\right)^{2}-\left(\sum \mathrm{x}\right)^{2}\right\}\left\{\mathrm{n}\left(\sum \mathrm{xy}\right)^{2} \cdot\left(\sum \mathrm{y}\right)^{2}\right.}\right\}}
$$

Setiap jawaban yang diperlukan oleh responden diberi nilai dengan ketentuan : Sangat baik nilai $=5$, Baik nilai $=4$, Cukup nilai $=3$, Kurang nilai $=2$, Tidak baik nilai $=1$,

Kemudian untuk penentuan kinerja dan skala responden digunakan formula :

Interval $=\underline{\text { Nilai maksimum }- \text { Nilai minimum }}$ Jumlah Kelas

\section{HASIL DAN PEMBAHASAN}

Data yang disajikan pada bab ini adalah data yang diperoleh dari hasil 2 angket terhadap 8 orang responden. Angket pertama berisi 13 pertanyaan sedangkan angket kedua berisi 10 pertanyaan. Dari 7 buah angket yang disebarkan dapat terkumpul seluruhnya.
Dari angket 1 menjaring tentang data kompensasi atau variabel bebas. Angket 2 menjaring data tentang efektivitas kerja karyawan atau untuk variabel terikat. Setiap angket tersedia 5 alternatif jawaban yang telah tersedia. Angket seperti ini lebih dikenal sebagai angket tertutup. Hampir semua karyawan merasa puas dengan gaji pokok yang mereka terima setiap bulannya, yaitu :

\section{Korelasi antara Kompensasi Terhadap Efektivitas Kerja Karyawan}

Untuk mengetahui signifikan atau tidaknya korelasi antara kompensasi terhadap efektivitas kerja karyawan, maka diperlukan beberapa langkah kerja karena kedua variabel tersebut berskala interval atau rasio, maka digunakan rumus korelasi analisis regresi linear sederhana. Dalam penelitian ini data mentah yang diperoleh dari angket yang telah disebarkan kepada 8 orang responden. Adapun data-data yang didapat ditabulasikan sebagai berikut:

Table 1. Data Mentah Variabel X dan Y

\begin{tabular}{ccc}
\hline No & $\begin{array}{c}\text { Kompensasi } \\
(\mathbf{X})\end{array}$ & $\begin{array}{c}\text { Efektivitas Kerja } \\
(\mathbf{Y})\end{array}$ \\
\hline 1 & 44 & 45 \\
2 & 47 & 39 \\
3 & 46 & 46 \\
4 & 36 & 47 \\
5 & 39 & 48 \\
6 & 37 & 49 \\
7 & 33 & 30 \\
8 & 37 & 34 \\
\hline
\end{tabular}

Tabel 2. Hasil Analisis Regresi Sederhana Coefficients ${ }^{\text {a }}$

\begin{tabular}{cccccc}
\hline Model & Unstandardized Coefficients & $\begin{array}{c}\text { Standardized } \\
\text { Coefficients }\end{array}$ & t & Sig. \\
& $\mathrm{B}$ & Std. Error & & & \\
\hline 1 (Constant) & -25.805 & 21.574 & .299 & 1.196 & .277 \\
kompensasi & .412 & .537 & & 10.768 & .472 \\
& & & & &
\end{tabular}

a. Dependent Variable: Efektivitas Kerja 
berikut:

Persamaan regresinya sebagai

$\mathrm{Y}^{\prime}=\mathrm{a}+\mathrm{Bx}$

$Y^{\prime}=-25.804+0.412 X$

Angka-angka ini dapat diartikan sebagai koefisien regresi variabel kompensasi (X) sebesar 0.412; artinya jika kompensasi mengalami peningkatan 1, maka efektivitas kerja (Y') akan mengalami peningkatan sebesar 0,412 . Koefisien bernilai positif artinya terjadi hubungan positif antara kompensasi terhadap efektivitas kerja, semakin tinggi kompensasi maka semakin meningkat efektivitas kerja.

Nilai efektivitas kerja, semakin tinggi kompensasi maka semakin meningkat efektivitas kerja.
Nilai efektivitas kerja yang diprediksi (Y') dapat dilihat pada tabel Resedual Statistics (kolom Predicate Value). Sedangkan Residual (unstandardized residual) adalah selisih antara Kompensasi dengan Predicate value dan Std. Residual (standardized residual) adalah nilai residual yang telah terstandarisasi (nilai semakin mendekati 0 maka model regresi semakin baik dalam melakukan prediksi, sebaliknya semakin menjauhi 0 atau lebih dari 1 atau -1 maka semakin tidak baik model regresi dalam melakukan prediksi (Dwi Priyatno, 2009).

Tabel 3. Casewise Diagnostics ${ }^{a}$

\begin{tabular}{crrrr}
\hline $\begin{array}{c}\text { Case } \\
\text { Number }\end{array}$ & \multicolumn{1}{c}{$\begin{array}{c}\text { Std } \\
\text { Residual }\end{array}$} & \multicolumn{1}{c}{$\begin{array}{c}\text { Efektivitas } \\
\text { Kerja }\end{array}$} & $\begin{array}{l}\text { Predicted } \\
\text { Value }\end{array}$ & \multicolumn{1}{l}{ Residual } \\
\hline 1 & .144 & 45.00 & 43.9513 & 1.04868 \\
2 & -.847 & 39.00 & 45.1886 & -6.18864 \\
3 & .168 & 46.00 & 44.7762 & 1.22380 \\
4 & .869 & 47.00 & 40.6518 & 6.34821 \\
5 & .837 & 48.00 & 41.8891 & 6.11089 \\
6 & 1.087 & 49.00 & 41.0642 & 7.93577 \\
7 & -1.289 & 30.00 & 39.4145 & -9.41447 \\
8 & -.967 & 34.00 & 41.0642 & -7.06423 \\
& & & & \\
\hline
\end{tabular}

a. Dependent Variable: Efektivitas Kerja

\section{Pengujian Hipotesis}

Hipotesis ini untuk membuktikan kebenaran, maka hasil yang diperoleh berdasarkan statistik dengan langkahlangkah sebagai berikut:

a. Menentukan hipotesis

Ho : Ada pengaruh secara signifikan antara Kompensasi terhadap efektivitas kerja karyawan

$\mathrm{Ha}$ : Tidak ada pengaruh secara signifikan antara Kompensasi terhadap efektivitas kerja karyawan

b. Menentukan sifat signifikansi

Tingkat signifikansi menggunakan $\mathrm{a}=5 \%$ (signifikansi $5 \%$ atau 0,005 ) adalah ukuran standar yang sering digunakan dalam penelitian.

c. Menentukan thitung

Berdasarkan tabel diperoleh T Hitung sebesar 10.768

d. Tabel distribusi $\mathrm{T}$ dicari pada $\mathrm{a}=5 \%$ : $2=2,5 \%$ (uji 2 sisi) dengan derkat kebebasan (df) n-k-1 atau 8-2-1 = 5 (n adalah jumlah kasus dan $\mathrm{k}$ adalah jumlah variabel independen). Dengan pengujian 2 sisi (signifikansi = 0,025 ) hasil

diperoleh untuk $\mathrm{T}$ tabel sebesar 2.571 . 
e. Kriteria pengujian

Ho diterima jika $-\mathrm{T}$ tabel $\leq \mathrm{T}$ hitung $\leq$ T tabel.

Ho ditolak jika - T hitung <-T tabel atau Thitung $>\mathrm{T}$ tabel.

f. Membandingkan $\mathrm{T}$ hitung dengan $\mathrm{T}$ tabel $(10,768>2,571)$ maka Ho ditolak.

g. Oleh karena nilai $\mathrm{T}$ hitung $>\mathrm{T}$ tabel $(10,768>2,571)$ maka Ho ditolak, artinya bahwa ada pengaruh secara signifikan antara kompensasi terhadap efektivitas kerja karyawan. Jadi dalam kasus ini dapat disimpulkan bahwa kompensasi berpengaruh terhadap Efektivitas kerja pada BMT Septa Bina Usaha Pekanbaru.
Untuk dapat menganalisa keseluruhan data dan untuk dapat mengetahui bagaimana Efektivitas Kerja Karyawan BMT Septa Bina Usaha Pekanbaru, maka langkah yang harus dilakukan adalah meraup seluruh hasil angket terhadap 8 orang karyawan. Setiap jawaban diberi skor, untuk alternatif jawaban 1 diberi skor 5, jawaban 2 diberi skor 4 , jawaban 3 skornya 3 dan jawaban 4 diberi skor 2 , serta jawaban 5 diberi skor 1 .

Permasalahan pertama yang diberi jawabannya dalam penelitian ini adalah bagaimana Efektivitas Kerja Karyawan BMT Septa Bina Usaha dapat dilihat pada tabel berikut :

\section{Efektivitas Kerja Karyawan}

Tabel 4. Data Skor Efektivitas Kerja Karyawan

\begin{tabular}{cc}
\hline No & Efektivitas Kerja \\
\hline 1 & 45 \\
2 & 39 \\
3 & 46 \\
4 & 47 \\
5 & 48 \\
6 & 49 \\
7 & 30 \\
8 & 34 \\
\hline
\end{tabular}

Dari data di atas dapat diketahui bahwa, skor tertinggi adalah 49 dan yang terendah adalah 34 .

Tabel 5. Persentase Variabel Efektivitas Kerja Karyawan

\begin{tabular}{cccc}
\hline Inteval Skor & F & Persentase & Keterangan \\
\hline $40-49$ & 5 & 62,5 & Tinggi \\
$30-39$ & 3 & 37,5 & Sedang \\
$20-29$ & - & - & Rendah \\
\hline Jumlah & 8 & $100 \%$ & \\
\hline
\end{tabular}

Berdasarkan pada tabel di atas
dapat diketahui bahwa tingkat
erfektivitas Kerja Karyawan termasuk
dalam tingkatan tinggi, yaitu 5 atau
$62,5 \%$ dan yang mendapat tingkatan

sedang 3 atau 37\% dan tidak ada satupun yang mendapat tingkatan rendah.

\section{Jawaban Permasalahan}

Seperti yang dikemukakan pada Bab I bahwa ada dua permasalahan yang 
dicari jawabannya dalam penelitian ini. Kedua permasalahn itu telah ditemukan jawabannya. Adapun permasalahannya adalah :

a. Apakah terdapat pengaruh antara kompensasi terhadap efektivitas kerja karyawan BMT Septa Bina Usaha Pekanbaru?

Oleh karena nilai $\mathrm{t}$ hitung $>\mathrm{t}$ tabel $(10,768>2,571)$ maka Ho ditolak, artinya bahwa ada pengaruh secara signifikan antara kompensasi terhadap efektivitas kerja karyawan pada BMT Septa Bina Usaha Pekanbaru.

b. Apakah terdapat Hubungan Manajemen dengan Karyawan Septa Bina Usaha Pekanbaru?

Setelah penelitian dilakukan maka ditemukan dalam tingkatan tinggi, yaitu 5 atau $62,5 \%$ dan yang mendapat tingkatan sedang $37,5 \%$, sedangkan untuk tingkatan rendah tidak ada.

langsung (kesejahteraan) berbentuk uang dan barang (natura) supaya dapat merangsang gairah dan kepuasan kerja karyawan serta mendorong terwujudnya sasaran perusahaan.

Dari penelitian dan pembahasan yang dilakukan maka dapat diambil kesimpulan bahwa :

a. Oleh karena nilai $\mathrm{t}$ hitung $>\mathrm{t}$ tabel $(10,768>2,571)$ maka Ho ditolak, artinya bahwa ada pengaruh secara signifikan antara kompensasi terhadap efektivitas kerja karyawan. Jadi dalam kasus ini dapat disimpulkan bahwa kompensasi berpengaruh terhadap Efektivitas kerja karyawan pada BMT Septa Bina Usaha Pekanbaru.

b. Setelah penelitian dilakukan maka ditemukan bahwa tingkat efektivitas kerja karyawan termasuk dalam tingkatan tinggi, yaitu 5 atau $62,5 \%$ dan yang mendapat tingkatan sedang $37,5 \%$ sedangkan untuk tingkatan rendah tidak ada.

\section{KESIMPULAN}

Berdasarkan penelitian yang telah kami lakukan ditemukan banyak hal yang mempengaruhi Efektivitas kerja karyawan termasuk di dalamnya kompensasi yang memiliki peranan penting. Karena kompensasi merupakan tolak ukur dalam mensejahterakan karyawan. Maka sebaiknya pihak-pihak manajemen lembaga atau perusahaan dapat memahami akan arti pentingnya kompensasi tersebut, Kebijaksanaan kompensasi, baik besarnya, susunannya, maupun waktu pembayarannya dapat mendorong gairah kerja dan keinginan karyawan untuk mencapai prestasi kerja yang optimal sehingga membantu terwujudnya sasaran perusahaan.

Susunan kompensasi hendaknya disusun dengan unsur-unsur yang terdiri dari kompensasi langsung (gaji, upah, upah insentif). Kompensasi tidak

\section{Saran-saran}

Berdasarkan penelitian yang telah kami lakukan ada beberapa hal yang ingin disampaikan berupa saran yang membangun demi tercapainya harapan efektivitas kerja yang semakin baik:

a. Merujuk kepada ajaran Islam, disarankan kepada para pengusaha agar memberikan upah kepada para karyawan sesuai dengan keahlian yang mereka miliki, sesuai dengan Hadist Nabi yang menyatakan agar upah buruh dibayarkan sebelum keringat tubuhnya kering, artinya bayarkanlah gaji tersebut secara layak.

b. Kepada para pengusaha agar memberikan training-training diluar jam kerja kepada karyawannya, agar efektivitas kerja tersebut semakin baik.

c. Bagi para karyawan agar bekerjalah dan bermitra dengan atasan secara baik, serta menjalin kerjasama yang baik. 
d. Dan tidaklah ada yang sempurna di dunia ini, maka dari itu untuk para peneliti yang ingin meneliti dengan tema yang sama, untuk data menyempurnakan segala kekurangan yang ada di dalam penelitian kami ini, seperti menambah jumlah responden, memperbarui pertanyaan-pertanyaan yang ada di dalam angket, menambah daftar kepustakaan dan apa yang ditambahkan untuk mendekati kesempurnaan.

\section{DAFTAR PUSTAKA}

Abdul Futuh Shabri. 2007. Sukses Bisnis Berkat Wasiat Nabi. Pustaka AlKautsar. Jakarta.

Arikunto, Suharsimi. 1993. Prosedur Penelitian, Cetakan ke-II. Rineka Cipta. Yogyakarta.

Karim, Adimarwan. 2007. Sejarah Pemikiran Ekonomi Islam. Rajawali Press. Jakarta.

Dairi, Rizal. 2008. Metodolgi Penelitian. UIR Press. Pekanbaru.

Dairi, Rizal. 2008. Buku Pedoman Penulisan Usulan Penelitian (Proposal) Laporan Hasil Penelitian (skripsi). UIR Press. Pekanbaru.

Dwi Priyatno, 2009. Mandiri Belajar SPSS (Statistical Product and Service Solution) untuk data dan Uji Statistik. Media Kom. Jakarta.
Hasibuan, Malayu. 2008. Manajemen Sumber Daya Manusia. Bumi Aksara. Jakarta.

Insedewimme. Blogspot.com. Ubah dalam Islam. Google. Net

Mannan, Abdul. 1997. Teori dan Praktek Ekonomi Islam. PT. Dana Bakti Prima Jasa. Yogyakarta.

Martoyo, Susilo. 1999. Manajemen Sumber Daya Manusia edisi 4. BPFE. Yogyakarta.

Prima, Anestonandri. 2006. Marketing Research For Beginning. Penerbit Andi. Yogyakarta.

Rivai, Veithzal. 2004. Kepemimpinan dan Perilaku Organisasi. PT. Raja Grafindo Persada. Jakarta

Sinn, Ahmad Ibrahim Abu. 1996. Manajemen Syariah. PT. Raja Grafindo. Jakarta.

Sugiono. 2008. Metode Penelitian Administrasi. Alfabet. Bandung.

Suprapto. 2000. Metode Ramalan. Kuantitatif untuk Perencanaan Eko dan Bisnis. PT. Rineka Cipta. Jakarta.

Syaikh Nashr bin Muhammad bin Ibrahim. 2003. Akhlak dan Etika Mukmin. Inti Media: Jakarta.

Yaslis, Ilyas. 2006. Kiat. Sukses Manajemen Tim Kerja. PT. Gramedia Pustaka Utama. Jakarta. 